\title{
Experts publish revised Standards in Dentistry
}

A comprehensive collection detailing guidance and standards for primary dental care has been published by the Faculty of General Dental Practice (FGDP $[\mathrm{UK}]$ ) in its second edition of Standards in Dentistry.

This publication for general dental practitioners and their teams is a guide to personal or practice-based quality assessment and sets out specific standards

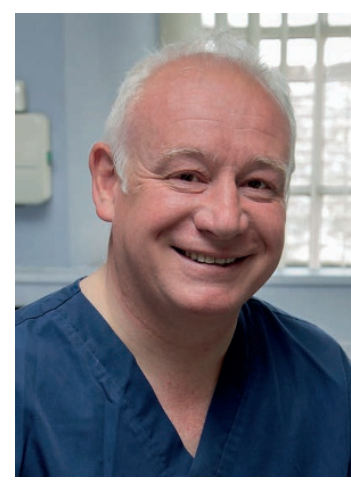
covering many areas including consultation and diagnosis, paediatric dentistry, orthodontics, management of acute pain, periodontics, endodontics, removable partial dentures, complete dentures, minor oral surgery, implant dentistry, management of dental trauma, direct, coronal and root surface restorations, and indirect coronal restorations.

It also summarises almost 70 standard and guideline publications by the Faculty and 30 other organisations, encompassing emergency dental care, examination and record-keeping, infection prevention and control, medical emergencies, medications management, oral health, pathology, patient information, practice management, prevention, radiography, restorative dentistry, risk management and communication, sedation, special care dentistry and staff training.

This second edition of the publication was carried out by Professor David Moles and his colleagues at Peninsula Dental School, Ewen McColl, Christopher Tredwin, Robert Witton and Lorna Burns, and its publication follows consultation with a wide range of national dental bodies.

Contemporary clinical, organisational and dento-legal contexts for dentistry have been taken into account in the new book, as well as changes in the evidence base since the first edition was published in 2006.

Standards for making and receiving referrals, and for oral medicine, are included for the first time, and the book includes a section on keeping up-to-date with changing guidelines and standards over time.

Ian Mills (pictured), Dean of FGDP(UK), said: 'The Faculty's core function is to raise the standards of care delivered to patients, and the provision of guidance and standards by dentists, for dentists, is central to this.

'This second edition of Standards in Dentistry is an indispensable reference guide which will assist the whole dental team in identifying appropriate standards for the delivery of high-quality care.'

The publication will be sent to all Faculty members and non-members can buy it for $£ 44.99$ at www.fgdp.org.uk/shop.

1. FGDP. Standards in Dentistry (September 2018). Available at https://www.fgdp.org. uk/shop/books/standards-dentistry (accessed 2 October 2018). 